\title{
The differential equation research on design control of mooring system
}

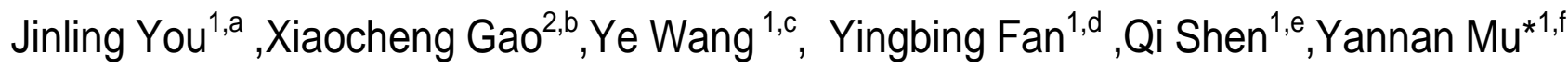 \\ ${ }^{1}$ School of science, Heihe University, 164300, Heihe City of Heilongjiang, China \\ ${ }^{2} \mathrm{Cpc}$ committee office,Heihe University, 164300, Heihe City of Heilongjiang, China \\ ayjl19630330@126.com, b270670891@qq.com, ${ }^{\mathrm{c}} 13949263 @ q q . c o m$, \\ d276251052@qq.com, ${ }^{\mathrm{e}} 56385355 @ q q . c o m,{ }^{f} \mathrm{myn} 17 @ y e a h . n e t$
}

Keywords: Mooring system,System optimization, Morison formula, Stress analysis.

\begin{abstract}
In this paper, through research and analysis of mooring system composition, advantages and disadvantages and single point mooring compared to the limitations of multi-point mooring system, etc. Mainly used the finite element model and combining with the method of integral control of the cable equation analysis to solve the system under the action of static and dynamic movement and stress distribution of the system. We carefully analyzed the influence of different conditions on the system, the impact of some of the smaller factors such as wave forces applied Morison formula are analyzed. For some in the actual operation of the larger impact on the system factors such as the weight of the chain, the material, the wear and tear, we design a new index system to analyze it, optimization of the whole system.
\end{abstract}

\section{Introduction}

According to the relative nearly shallow sea observation of some relevant data, to establish the mathematical model for the following research problem. Due to the influence of various factors such as tidal environment, considering the force of wind, current and depth of the mooring system design case, the study when the cloth off the measured depth between $16 \mathrm{~m}$ to $20 \mathrm{~m}$. And water velocity of the cloth point maximum of $1.5 \mathrm{~m} / \mathrm{s}$, up to a maximum of $36 \mathrm{~m} / \mathrm{s}$ wind speed. Analysis different Shi Gang barrel, steel Angle work best at what Angle, at this time the shape of the chain, buoys draft depth and the range of the swimming area.

Table 1 Chain type and parameter list

\begin{tabular}{ccc}
\hline Model & Length(mm) & The quality of the unit length $(\mathrm{kg} / \mathrm{m})$ \\
\hline I & 78 & 3.2 \\
II & 105 & 7 \\
III & 120 & 12.5 \\
IV & 150 & 19.5 \\
V & 180 & 28.12 \\
\hline
\end{tabular}

\section{Problem analysis}

In considering, water power, wind power and the depth of the water circumstances, establish relevant mathematical model, design a new mooring system, under different conditions is analyzed on the steel drum, steel Angle; Chain shape, water depth of the buoy and swimming area. At the same time, analysis the influence of different conditions on the system and optimize the system. (cloth off the measured depth between 16 and $20 \mathrm{~m}$.

\section{Model assumes}


(1) No water resistance;

(2)Regardless of the heavy ball hanging on the rope;

(3)Assuming that the steel barrel and steel pipe joint for welding;

(4)In this article $g=10 \mathrm{~m} / \mathrm{s}^{2}$ and $\pi=3.14$.

\section{Model establishment and solve}

Build a model . Environmental load of mooring system design mainly by wind, waves, temperature, such as tidal load caused by natural environment, has a great influence on the wind load, wave load and so on. The topic mainly aroused by the tidal water flow speed in the impact on the mooring system. Can according to the mooring system design environment conditions to calculate. Offshore water force can be calculated by approximate formula $\mathrm{F}=0.625 \mathrm{x}$ Sv2, including $\mathrm{S}$ for objects in the water flow velocity plane projection area $(\mathrm{m} 2), \mathrm{v}$ is the water velocity $(\mathrm{m} / \mathrm{S})$.In ocean engineering, when the object scale is relatively small, negligible effect on wave motion object, when D/L0.2 artifacts ( $\mathrm{D}$ is the characteristic length of the object), known as the small scale component, calculating the wave forces on the small scale component we Morison formula: (available: the density of sea water; damping coefficient and inertia coefficient; cable diameter; : micro period of midpoint water points of horizontal velocity; micro level acceleration period of midpoint water points; micro length)

$$
d F=\frac{1}{2} \rho_{W} C_{d} D\left|V_{X}\right| V_{X} d z+\rho_{W} C_{M} \frac{\pi D^{2}}{4} \dot{v}_{X} d z
$$

The study of the joint action of wave and flow is very complex, and can't separate studies, we check it on the website to study the following formula:

The drag force vector:

$$
F_{D}=\frac{1}{2} C_{D} \rho_{W} D\left(V+V_{C}\right)\left|V+V_{C}\right|
$$

Component:

$$
\begin{gathered}
F_{D x}=\frac{1}{2} C_{D} \rho_{W} D\left(V+V_{C} \cos \varphi\right)\left|V+V_{C}\right|, \\
F_{D y}=\frac{1}{2} C_{D} \rho_{W} D V_{C} \sin \varphi\left|V+V_{C}\right|
\end{gathered}
$$

Among them

$$
\left|V+V_{C}\right|=\left[\left(V_{x}+V_{c} \cos \varphi\right)^{2}+\left(V_{c} \sin \varphi\right)^{2}\right]^{\frac{1}{2}} .
$$

Considering the effects of a current wave forces acting on the floating body formula:

$$
\begin{gathered}
d F_{x}=\frac{1}{2} C_{d} \rho_{W} D\left(V+V_{C} \cos \varphi\right)\left|V+V_{C}\right| d z+\rho C_{M} \frac{\pi D^{2}}{4} \dot{V}_{X} d a \\
d F_{y}=\frac{1}{2} C_{D} \rho_{W} D V_{C} \sin \varphi\left|V+V_{C}\right| d z
\end{gathered}
$$

( $V$ : wave speed; $V_{C}$ : water flow speed; ${ }^{\varphi}$ : flow and wave propagation direction Angle;

$V_{X}$ : wave speed of water quality value)

In the mooring system, the weight of the chain and materials had a great influence on the whole system. Synthesis of mooring line with steel cable, the structure of the mooring line is completely different. And the differential of the cable can be thought of as a circular helix. As a result, the spiral radius, pitch, the cable specification is one of the important parameters of the cable characteristics. For the cable damage on the influence of the mooring system, a model of damage evaluation index is given $\left(\varepsilon_{m}\right.$ : By the maximum deformation of the definition of an element; ${ }^{\varepsilon_{t}}$ : Damage before 
must transcend the distortion of the benchmark; $\varepsilon_{b}$ : A unit under the effect of one-way reaches maximum stress deformation; $\alpha_{1 /} \beta_{1}$ : Damage parameter) :

$$
D=\alpha_{1} \frac{\varepsilon_{m}-\varepsilon_{t}}{\varepsilon_{b}} \beta_{1} \text {. }
$$

Discover the data of the experiment and the using of the internet. Polyester rope tension deformation and act on it is there is no linear relationship, and time characteristics. To this, we can based on polyester rope of young's modulus $\mathrm{E}$ and the experience formula of the density ratio ( $\rho$ : Polyester rope density; $L_{m}$ : the average tension; $L_{\alpha}$ : tension amplitude; $\tau$ : incentive cycle; $\alpha / \beta / \gamma / \sigma$ : The corresponding coefficient) :

\section{Solve the model}

$$
\frac{E}{\rho}=\alpha+\beta L_{m}-\gamma L_{\alpha}-\sigma \log (\tau)
$$

Use the time domain analysis method to analyze three describes problems, in view of the dynamic analysis system, with time as the reference, the actual state of real reaction system balance equation at the same time. When the study area always, but through the Fourier transform and inverse transformation, to realize the frequency domain and time domain transformation. For chain control equation, we use the finite element method (fem) model method. Control equations of chain (finite element method):

$$
\begin{gathered}
l=\frac{1}{w_{\text {chain }}} \int_{0_{\theta}}^{\theta} \frac{T_{\text {level }}}{\cos ^{2} \theta} d \theta=\frac{T_{\text {level }}}{w_{\text {chain }}} \tan \theta \\
x=\frac{1}{w_{\text {chain }}} \int_{\theta_{0}}^{\theta} \frac{T_{\text {level }}}{\cos \theta} d \theta=\frac{T_{\text {level }}}{w_{\text {chain }}} \ln \left(\frac{1}{\cos \theta}+\tan \theta\right)
\end{gathered}
$$

According

$$
\begin{gathered}
d z=\sin \theta d l \\
Z=\frac{1}{w_{\text {chain }}} \int_{0}^{\theta} \frac{T_{\text {level }} \sin \theta}{\cos ^{2} \theta} d \theta=\frac{T_{\text {level }}}{w_{\text {chain }}}\left(\frac{1}{\cos \theta}-1\right), \\
\left(F_{\text {buoy }}+F_{\text {single i }}\right)=\left(G_{\text {buoy }}+G_{\text {single }}\right)+\left(T_{\text {total }}-\frac{G_{\text {single i }}}{\cos \theta \mathrm{i}}\right) \times \cos \theta \mathrm{i} \\
\left(T_{\text {total }}-\frac{G_{\text {single i }}}{\cos \theta \mathrm{i}}\right) \sin \theta \mathrm{i}=F_{\text {wind }}, \\
M \ddot{r}-\left(\bar{\lambda} r^{\prime}\right)^{\prime}=q, \\
M=\rho_{1} A_{i}+\rho_{f} A_{i} C_{M n}(1+\varepsilon) N+\rho_{f} A_{i} C_{M t}(1+\varepsilon) T, \\
\bar{\lambda}=T /(1+\varepsilon), \\
\bar{\varepsilon}=\bar{\lambda} / E A, \\
\varepsilon=T / E A=\bar{\lambda} /(E A-\bar{\lambda}), \\
r^{\prime}=\left[\begin{array}{ll}
r_{1}^{\prime} r_{2}^{\prime} r_{3}^{\prime}
\end{array}\right]^{T}, \\
{\left[\begin{array}{lll}
r_{1}^{\prime} r_{1}^{\prime} & r_{1}^{\prime} r_{2}^{\prime} & r_{1}^{\prime} r_{3}^{\prime} \\
r_{2}^{\prime} r_{1}^{\prime} & r_{2}^{\prime} r_{2}^{\prime} & r_{2}^{\prime} r_{3}^{\prime} \\
r_{3}^{\prime} r_{1}^{\prime} & r_{3}^{\prime} r_{2}^{\prime} & r_{3}^{\prime} r_{3}^{\prime}
\end{array}\right],} \\
r^{\prime} r^{\prime}, 1
\end{gathered}
$$




$$
\begin{gathered}
T=r^{\prime} r^{T} /(1+\varepsilon)^{2}, \\
N=I-T .
\end{gathered}
$$

I is Unit matrix. $M$ is Mass matrix. $\bar{\lambda}$ is Effective tension. $\mathrm{q}$ is the external force matrix (All qualified external forces ). Chain on the flow of energy by Morrison equation:

$$
\begin{gathered}
q_{f}=\rho_{f} A_{i}(I+\varepsilon)\left(C_{M n} N+C_{M t} T\right)\left(a_{f}-\ddot{r}\right)+0.5 \rho_{f} D_{f} C_{D n}(I+\varepsilon) N\left(V_{f}-\dot{r}\right)\left|N\left(V_{f}-\dot{r}\right)\right| \\
+0.5 \rho_{f} D_{f} C_{D t}(I+\varepsilon) T\left(V_{f}-\dot{r}\right)\left|T\left(V_{f}-\dot{r}\right)\right|
\end{gathered}
$$

$\rho_{f}$ The density of water, ${ }^{A_{i}}$ Outside the chain of cross-sectional area, $D_{f}$ The diameter of the cable, $V_{f}$ Water flow rate, ${ }^{a} f$ The flow acceleration, $C_{M n}, C_{M t}, C_{D n}, C_{D t}$ Method to the added mass coefficient, respectively, Tangential, added mass coefficient method to the drag force coefficient and the tangential drag force coefficient.

$$
\begin{gathered}
q=\left(\rho_{f} A_{f}-\rho_{i} A_{i}\right) g e_{y}+\rho_{f} A_{i}(I+\varepsilon)\left(I+C_{M n} N+C_{M t} T\right)+0.5 \rho_{f} D_{f} C_{D n}(I+\varepsilon) N\left(V_{f}-\dot{r}\right)\left|N\left(V_{f}-\dot{r}\right)\right| \\
+0.5 \rho_{f} D_{f} C_{D t}(I+\varepsilon) T\left(V_{f}-\dot{r}\right)\left|T\left(V_{f}-\dot{r}\right)\right|
\end{gathered}
$$

$e_{y}$ The unit vector along y direction, $\rho_{t}$ The cable material density, $A_{t}$ Cross-sectional area of the chain 。Cable shape above it no longer drawing, the rest of the data is as follows:

When $v_{\text {wind }} \leq 36 \mathrm{~m} / \mathrm{s} ; \quad v_{\text {water }} \leq 1.5 \mathrm{~m} / \mathrm{s}$ A combination of the above formula:

$$
\begin{gathered}
\mathrm{h}=0.83 \mathrm{~m}, \theta_{4}=1.889, \theta_{3}=1.999, \theta_{2}=2.094, \theta_{1=2.956, \alpha=2.214, \mathrm{~s}=685.85 .} . \\
\mathrm{h}=0.82 \mathrm{~m}, \theta_{4}=2.348, \theta_{3}=2.428, \theta_{2}=2.514, \theta_{1=2.624,} \alpha=2.715, \mathrm{~s}=841.6 . \\
\mathrm{h}=0.80 \mathrm{~m}, \theta_{4}=3.210, \theta_{3}=3.025, \theta_{2}=3.1520, \theta_{1=3.154,} \alpha=3.248, \mathrm{~s}=915.2 . \\
\mathrm{h}=0.75 \mathrm{~m}, \theta_{4}=3.754, \theta_{3}=3.845, \theta_{2}=3.846, \theta_{1=3.9414,} \alpha=4.155, \mathrm{~s}=1028.55 . \\
\mathrm{h}=0.72 \mathrm{~m}, \theta_{4}=4.554, \theta_{3}=4.641, \theta_{2}=4.841, \theta_{1=4.8554,} \alpha=4.946, \mathrm{~s}=1124.5 .
\end{gathered}
$$

\section{Acknowledgments}

This work was financially supported by the University Nursing Program for Young Scholars with Creative Talents in Heilongjiang Province (No.2015114) and the Teaching Reform Research Project of Heihe University (xjg1502 ).

\section{References}

[1] H.M .Zhang, J.M .Yang and L.F.Xiao: China offshore platform, Vol. 12 (2004) No.5, p. 1-6.

[2] R.p Li, Y.H. Xie and S.Z: China offshore platform, Vol. 19 (2003) No.3, p. 1-5.

[3] F.J. X.L. Huang: Journal of Shanghai jiaotong university, Vol. 2 (2007) No.9, p.172-176.

[4] X.L Huang,X.H. Chen, F. J: Journal of Shanghai Jiaotong University. Vol. 10(2001) No.10, p. 2001-1470.

[5]Y. Xiao:Mooring system time-domain nonlinear analysis . (Ph.D.,Dalian University of Technology, China 2005), p.28.

[6] W.Huang,H. Liu:Ocean engineering. Vol. 4(2009) No.29, p. 140-2009. 